\title{
NUMERICAL DISCRETISATION OF BUILT STRUCTURES ASSUMPTION AND REALITY
}

\author{
M. Gutermann*, C. Schröder \\ University of Applied Sciences Bremen, Institute for Experimental Static, Neustadtswall 30, Bremen, Germany \\ * corresponding author: marc.gutermann@hs-bremen.de
}

ABstract. The second half of the 20th century was affected by the introduction of electronic data processing. The numerical methods appeared to be capable of solving every engineering problem. However, dealing with real problems, an appropriate numerical discretization of built structures is in many cases a difficult task, since fundamental input data concerning the actual properties of the structure, material and mechanical boundary condition couldn't always be met. Typical difficulties are an incomplete documentation, unknown effects of structural faults and uncertain material properties. In this paper our experience in experimental assessment of structures is described and the outcome of experimental versus numerical results is compared in several examples. This paper summarizes finally both prospects and limitations of numerical simulations of built structures and shall show that the identified load bearing capacity is strongly bound to the quality of the numerical structural model.

KEYWORDS: numerical discretisation, hybrid static, load tests, bridge, foundation, carousel.

\section{INTRODUCTION}

"A mathematical or mechanical model may be almost perfect - it stays a model". This citation from Prof. Opitz (TU Dresden) points to the fact that many students and even some engineers believe in computational results without reflection since a computers calculation seems always correct. The truth is that the results are as good as their assumptions which lay hopefully always on the safe side.

More and more existing structures have to be assessed according their serviceability and load carrying safety. The common procedure and solution strategies are shown in Fig. 1. But even numerical assessment requires input data concerning actual material and structural properties as well as mechanical boundary conditions. These preconditions could not always be met so that not any calculated proof is successful. Possible reasons are an incomplete documentation, unknown effects of structural faults and uncertainties in the modelling of the structural system with appropriate boundary conditions. Another problem occurs if the structures have a historic design: the current technical recommendations are made for building of (new) structures and does not meet the requirements to assess historic designs.

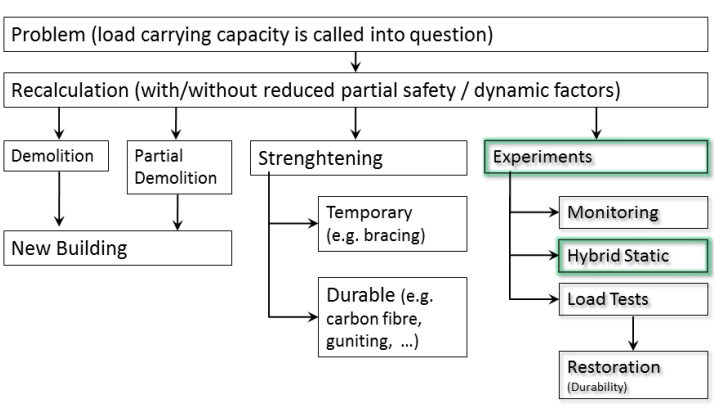

Figure 1. Solution Strategies to asses load carrying capacity of built structures

A parallel application of computational and experimental methods allows improving the numerical model and leads mostly to a much higher assessment of load carrying capacity, since the calibrated discretisation predicts the structural behaviour in a more realistic way (so called hybrid static - Fig. 11). On the basis of the experimental observation, the input parameters required for the analysis are obtained, e.g. to assess a railway bridge (see Fig. 2). The modelling of boundary conditions as well as material parameters were calibrated using experimental results and led to a more realistic folded-plate-discretisation (see Fig. 3). All loadings, recommended by guidelines, could be calculated using this model and sufficient load bearing capacity was proved. The advantage of subsequent extrapolating analysis is its totally non-destructive character. However, the disadvantage is the remaining uncertainty concerning the correctness of a numerical extrapolation. Parametric studies or the consideration of large safety margins are means for handling these uncertainties. 


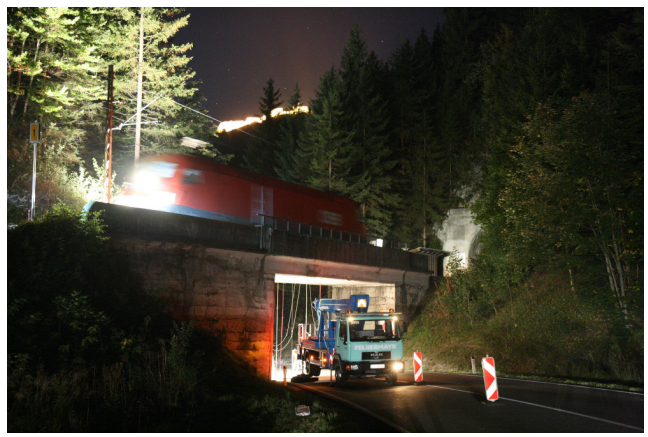

FiguRE 2. Measurements during operation

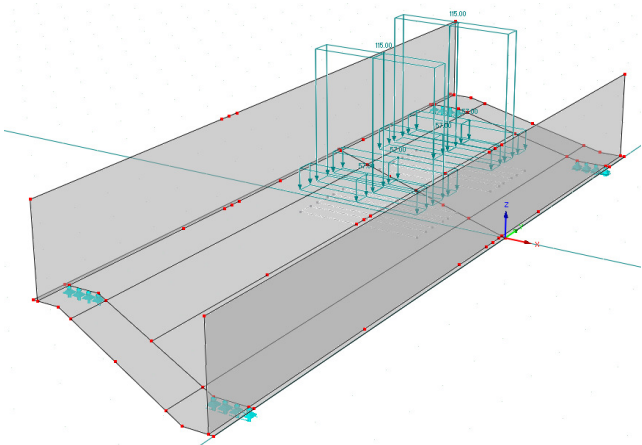

FiguRE 3. FE-Model, parameters calibrated by measurements

The following chapters give some examples how experimental data supplement numerical assessment and which advantages result hence.

\section{Case Studies}

\subsection{Masonry Arch Bridge "Clevertorbrücke", Hanover}

The stone masonry arch bridge crosses the river Leine in the center of Hanover to transfer a multi-lane principal road. A recurring inspection revealed several open joints, where the mortar has been deeply washed out. An engineering office measured the actual shape of the three-center arch as well material properties. First numerical discretisation, taking only the arch into account as load-carrying member, showed that the bridge should have collapsed under its self-weight already. It seemed obvious that the chosen assumptions did not fit the actual load transfer so that a second calculation took backfill into account 1, 2]. This showed a higher load carrying capacity, but revealed two aspects: first, the proven load-carrying capacity was still too low for high frequented roads; second, the load carrying transfer was a theoretical assumption and could not be proven without experimental confirmation. Since load carrying behaviour of backfill may be non-linear, we chose test loading with a special vehicle [3] (see Fig. 4).

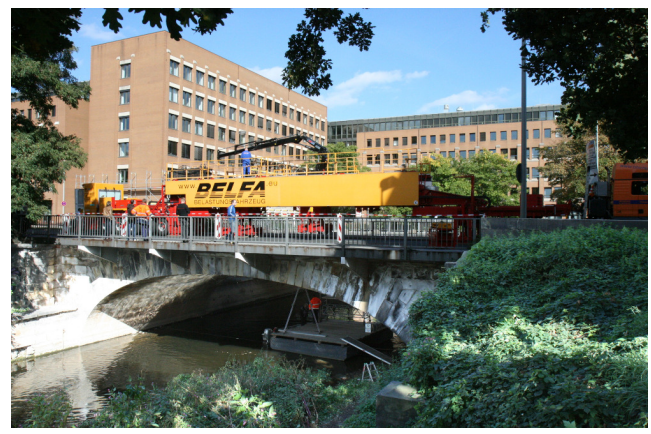

Figure 4. BELFA Test Loading of Stone Masonry Arch Bridge, Hanover

The results showed, that there was an effective load transfer in the backing and that this influence stays constant even at higher load levels including partial safety factors (see Tab. 1). With the experimental results it was possible to calibrate Finite Elements Models afterwards, even simple beam-spring-models, since it was possible to choose all unknown parameters as spring stiffness or boundary conditions.

In summary many influences (e.g. back filling, effective constraints, ...) supports in fact the load carrying system [4, but cannot be considered in calculations without experimental evaluation, especially if their load carrying behaviour may be non-linear at higher stress levels.

\subsection{Reinforced Concrete Foundations of Wind Energy Converters}

In the first decade of this century several reinforced concrete foundations of onshore wind energy converters showed defects as cracks and spalling at concrete surface. Some defects had simple causes as shrinkage or creeping but some defects were more severe and led to shut-down of sites (see Fig. 5). One incorrect approach had been, that the foundation was preliminary constructed as a foundation of an immobile structure. In fact a wind energy converter is more likely a machine than an immobile construction. An experimental assessment of several affected construction showed under operation movements of several millimetres $(f \leq 2.3 \mathrm{~mm}$ ) between foundation surface and steel built-in-part. A simple post-calculation by hand confirmed the assessed dimension, although they contain only deformation caused by elongation of concrete or steel as well as materials effects (shrinkage or creeping). Poor workmanship may cause even higher deformations. Our investigations showed clearly that in case of machine foundations, not only forces but also deformations should be taken into account, especially constructing connections between different materials. 


\begin{tabular}{l|c|c|c|c|} 
Results & \multicolumn{2}{|c|}{ Calculation } & \multicolumn{2}{c|}{ Measurement } \\
& $\begin{array}{c}\text { (FE-Model with backing) } \\
\text { Strain } \\
\text { Action }\end{array}$ & $\begin{array}{c}\text { Deflection } \\
f[\mu \mathrm{m} / \mathrm{m}]\end{array}$ & $\begin{array}{c}\text { Strain } \\
\epsilon[\mu \mathrm{m} / \mathrm{m}]\end{array}$ & $\begin{array}{c}\text { Deflection } \\
\text { f[mm }]\end{array}$ \\
\hline \hline $\begin{array}{l}\text { Drive Through of Crane } \\
(\mathrm{G}=48 \mathrm{t})\end{array}$ & 19 & 0.33 & 5 & 0.35 \\
\hline $\begin{array}{l}\text { Test Load BK 16/16 } \\
\text { (incl. } \gamma \text { and Crane) }\end{array}$ & 56 & 0.92 & 35 & 0.7 \\
\hline $\begin{array}{l}\text { Test Load BK 30/30 } \\
\text { (incl. } \gamma \text { and Crane) }\end{array}$ & 97 & 1.57 & 85 & 1.2 \\
\hline
\end{tabular}

TABle 1. Comparison of Results at Arch Crown (FE-Model with backing vs. measurement)

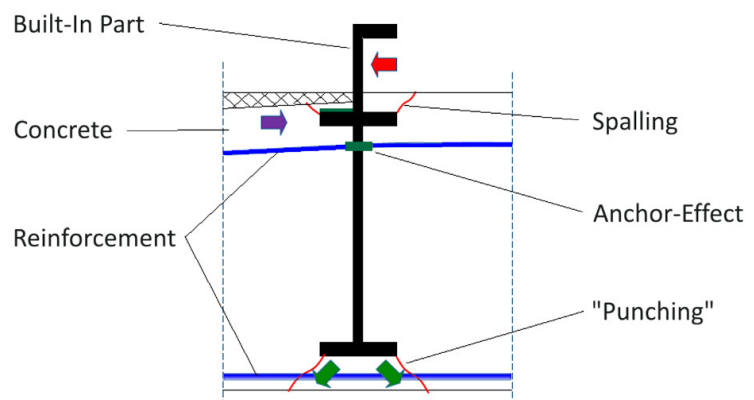

Figure 5. Double Flange Built-in Part and observed Defect Mechanism

\subsection{Carousel, Wuhan (China)}

After erection of a carousel the local authorities surveyed the construction by measuring strain at one of the main beams and compared these results with the submitted structural analysis of the construction. Unfortunately these values differ more than $200 \%$. We were invited to conduct additional measurements to investigate this deviation. We measured strains at the main beam at several positions (see Tab. 2 and compared the results with both simple bar model and 3D-FE-Model (see Fig. 6).

The results showed that the upper sensors close to the weld (d1Tk - d3Tk) measured much higher strains, caused to the influence of the nearby joint. Sensor d4Tk was situated out of the joints influence, removed more than half of the beam diameter (see Fig. 6. As a result this sensor showed appropriate values compared to both bar and 3D-FE-Model.
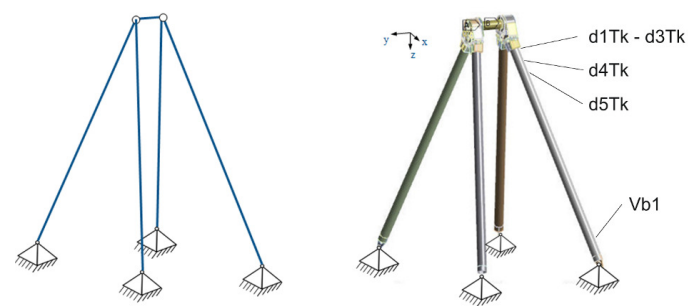

Figure 6. Bar- and 3D-FE-Model Model incl. sensor positions

In summary an experimental evaluation of calculations has to take into account which assumption had been made for the structural analysis. Otherwise the comparison will fail without being well founded.

\subsection{Steel Truss Bridge, Lomé (Togo)}

The state Togo built a steel truss bridge in the year 1960 to transport phosphates from inland to seaport (see Fig. 7). In the last decades more and more steel girders showed increasing deterioration by corrosion, obviously caused by the rough environmental conditions (high humidity, salt water, phosphates). It was decided to rehabilitate the bridge by replacing top and bottom chord during train operation. Fatigue had to be proven for the remaining girders, e.g. diagonals and support grid. A calculation had not given satisfactory results, so that additional information should be collected by on-site experiments and measurements including the verification of rehabilitation success.

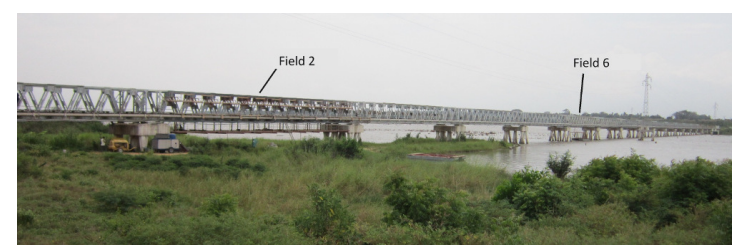

Figure 7. Steel Truss Bridge crossing the Lac Togo and tested fields

The results were diverging: Individual parts showed even higher values, but most stress levels were lower than calculated. The maximum reduction of more than $50 \%$ was reached at the grid beams. The following proof of fatigue showed that almost all members had a sufficient remaining live time of 20 years. 


\begin{tabular}{c|c|c|c|c|} 
Sensor & \multicolumn{2}{|c|}{$\begin{array}{c}\text { Average Measured Strain } \\
\text { Min }[\mu \mathrm{m} / \mathrm{m}]\end{array}$} & $\begin{array}{c}\text { Interference } \\
{[\mu \mathrm{m} / \mathrm{m}]}\end{array}$ & $\begin{array}{c}\text { Cal. Strain } \\
{[\mu \mathrm{m} / \mathrm{m}]}\end{array}$ \\
\hline \hline $\mathrm{d} 1 \mathrm{Tk}$ & -147 & 129 & \pm 40 & $\sim 190$ \\
\hline $\mathrm{d} 2 \mathrm{Tk}$ & -196 & 89 & \pm 50 & $\sim 143$ \\
\hline $\mathrm{d} 3 \mathrm{Tk}$ & -259 & 68 & \pm 50 & - \\
\hline $\mathrm{d} 4 \mathrm{Tk}$ & -95 & 128 & \pm 30 & $\sim 100$ \\
\hline $\mathrm{d} 5 \mathrm{Tk}$ & -62 & 56 & \pm 25 & - \\
\hline \hline $\mathrm{Vb} 1$ & -30 & 21 & \pm 1 & $26-47$ \\
\hline
\end{tabular}

TABle 2. Relative Deformation between Foundation Surface and Steel Built-In Part (double flange system)

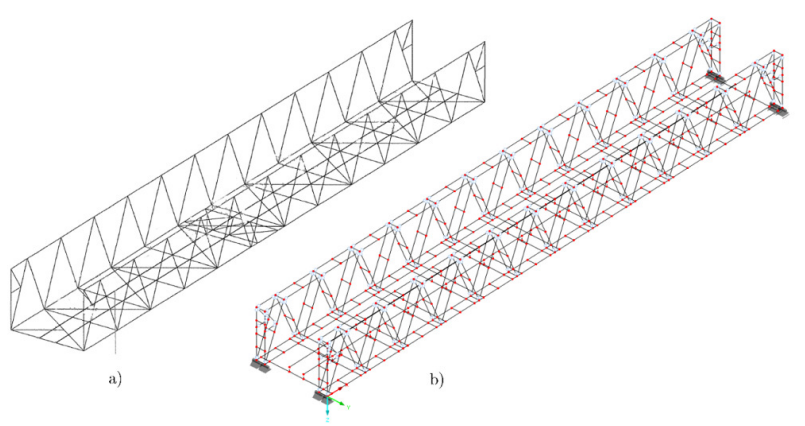

FIGURE 8. Influence of discretisation: a) simple spatial framework b) detailed dispersed truss

The experimental results were used afterwards to investigate the influence of calculational assumption on the stress level of truss members and consequentially on their remaining lifetime [5]. In the process the main emphasis was led on the discretisation of static system (see Fig. 8) and load application. This showed that the chosen loading (single load, partial distributed load) varied the results of grid beams for several ten percent, as measured and analysed. This was actually an exceptional outcome, all other investigated parameters, as

- Connection of truss members as hinge or rigid joints

- Consideration of sheet plates between truss members

- Realistic discretisation of boundary conditions

- Joint stiffness between longitudinal and cross beams

showed much lower influence, so that they can be generally neglected. In summary the investigations showed, that a more detailed spatial discretisation and especially a realistic load application can lead to much better results, even without experimental assessment. A simple analysis and discretisation of built structure is sufficient as a first approximation.

\section{Conclusions}

If we want to describe the physical reality using numerical discretisation we need additional information that may be gained by experiments, e.g. non-destructive testing, monitoring or load-tests. This may be cost and time consuming, but sometimes a little effort may have a great benefit. Our experiences, documented in this paper, are summarized with the following statements:

- A numerical Model stays Model, even if it seems perfect. Concomitant experimental analysis helps to improve significantly both model and results.

- Experimental evaluation should meet calculation assumptions. Otherwise they could not be compared.

- Many influences (e. g. Back filling, effective constraints, ...) support in fact the load carrying system, but cannot be considered in calculations without experimental evaluation, especially if their load carrying behaviour may be non-linear at higher stress levels.

- The calculated result is dependent on both system and boundary assumptions (especially in cases of arches and fatigue proof). Change of system parameters may vary the results by $100 \%$ or more.

- Discretisation of machine foundation should take (tolerable) deformations into account. An analysis as static and stiff system may not be sufficient and may lead to severe defects.

\section{ACKNOWLEDGEMENTS}

We want to send special thanks to the University of Applied Sciences Bremen and all involved parties, which enables us to have done more than 300 successful investigations in the field of analysing load carrying safety of built structures.

\section{REFERENCES}

[1] D. Proske, P. Lieberwirth, P. H. van Gelder. Sicherheitsbeurteilung historischer Steinbogenbrücken. Mauerwerk 11(4):186-189, 2007. DOI:10.1002/dama.200700327.

[2] Z. Orbán, M. Gutermann. Assessment of masonry arch railway bridges using non-destructive in-situ testing methods. Engineering Structures 31(10):2287-2298, 2009. DOI:dx.doi.org/10.1016/j.engstruct.2009.04.008

[3] M. Gutermann, C. Schröder. Loading vehicle belfa development and experience gained in 10 years of practice. Bridge Structures 11(1,2):19-31, 2015. DOI:10.3233/BRS-150081.

[4] M. Gutermann. An article on experimental assessment of structural safety of solid bridges. Proceedings of ICEM12-12 $2^{\text {th }}$ International Conference on Experimental Mechanics 28, 2004. 
[5] W. Malgut, K. Ammermann, T. Sander, M. Gutermann. Pont lagunaire, togo - Experimentelle Tragwerksanalyse einer Stahlfachwerkbrücke zum Nachweis der Restnutzungszeit. 8 Symposium "Experimentelle Untersuchungen von Baukonstruktionen" 2015. 